\title{
Numerical Simulation And Monitoring Analysis Of Deep Foundation Pit In Shijiazhuang Area
}

\author{
Zhang $\mathrm{Yu}^{1 \mathrm{~b}}, \mathrm{Yu} \mathrm{Li}^{2 \mathrm{a}^{*}}$, Liu Weichao ${ }^{3}$ \\ ${ }^{1}$ College of architecture and engineering, Hebei University, Baoding071000, China; \\ ${ }^{2}$ College of architecture and engineering, Hebei University, Baoding071000, China; \\ ${ }^{3}$ College of architecture and engineering, Hebei University, Baoding071000, China.
}

\begin{abstract}
The foundation pit engineering is a work with large amount of use and high difficulty coefficient. It is necessary to ensure the deformation of soil in the control range and the safety of the whole structure of the foundation pit. In this paper, the foundation pit support project in Shijiazhuang City, Hebei Province is taken as the research object, and the numerical analysis method is used to simulate the pile-anchor support in the First Section of the fourth section of the foundation pit. In this paper, the horizontal displacement value of deep foundation pit and the settlement value of the top edge of foundation pit are analyzed, It provides reference for future projects.
\end{abstract}

\section{Introduction}

With the appearance of a large number of high-buildings in cities, and the environmenl impact caused by the deformation of the retaining structure of foundation pit becomes more and more serious ${ }^{[1-3]}$. In view of how to accurately predict and control the deformation of the retaining pile, some scholars have done the relevant numerical analysis: Fang shijun ${ }^{[4]}$ combining the real deformation monitoring data and numerical simulation method of foundation pit row piles, the deformation laws of the pile body in different construction stages are summarized; Liu $\mathrm{Jie}^{[5]}$ established the finite element model and compared the results of the deformation simulation with the actual deformation monitoring results. It is concluded that the elastoplastic finite element simulation is close to the actual monitoring. Based on a deep foundation pit project in Shijiazhuang, this paper simulates the stability and deformation of the pile-anchor support structure. It can provide reference for similar projects in the future.

\section{Project Profile}

A foundation pit project in Shijiazhuang is taken as the research object. The excavation depth is $10 \mathrm{~m}$, the length is $120 \mathrm{~m}$, the width is $77 \mathrm{~m}$. The foundation pit belongs to the First Class Foundation pit, the corresponding safety structure importance coefficient is 1.1 .

\subsection{Overview Of Engineering Geology}

The construction site is located in the North China Plain area. Determine the soil parameters according to the field survey report, as shown in Table 1

Table 1 Mechanical indexes of man strata of proposed foundation pit

\begin{tabular}{|c|c|c|c|c|c|c|}
\hline Soil layer & $\begin{array}{l}\text { Thickness } \\
\text { of soil } \\
\text { layer(m) }\end{array}$ & $\begin{array}{l}\text { Unit weight, } \\
\gamma\left(k N / \mathrm{m}^{3}\right)\end{array}$ & $\begin{array}{l}\text { Cohesive } \\
\text { force, } \\
c_{k}(k P a)\end{array}$ & $\begin{array}{l}\text { Internal friction } \\
\text { angle, } \varphi\left(^{\circ}\right)\end{array}$ & $\begin{array}{l}\text { The characteristic value } \\
\text { of bearing capacity, } \mathrm{f}_{\mathrm{ak}} \\
(\mathrm{kPa})\end{array}$ & $\begin{array}{l}\text { Compression } \\
\text { modulus, Es } \\
(\mathrm{MPa})\end{array}$ \\
\hline $\begin{array}{l}\text { Miscellaneous } \\
\text { fill }\end{array}$ & 0.7 & 16 & 10 & 12 & 130 & 9.0 \\
\hline Silty clay & 4.0 & 17 & 3.0 & 27 & 140 & 8.6 \\
\hline Silty sand & 6.3 & 18 & 1.0 & 30 & 130 & 7.7 \\
\hline Medium sand & 0.9 & 19 & 0 & 34 & 130 & 12 \\
\hline Gravel sand & 12 & 19.7 & 0 & 35 & 170 & 7.0 \\
\hline Round sand & 15 & 20 & 0 & 35.5 & 160 & 15 \\
\hline
\end{tabular}




\section{Numerical simulation analysis}

\subsection{Modeling}

In order to carry out the reasonable simulation calculation, a cross section along the boundary line of the foundation pit is taken as the research object to carry out the two-dimensional calculation. This section adopts the form of pile-anchor support. In order to eliminate the boundary effect, the horizontal length of the model is 5 times the excavation depth, and the vertical length is 4 times the excavation depth [6-7]. The size of the model is $50 \mathrm{~m}, 40 \mathrm{~m}$ (length and width). There are 1015 solid elements at the excavation of the foundation pit.

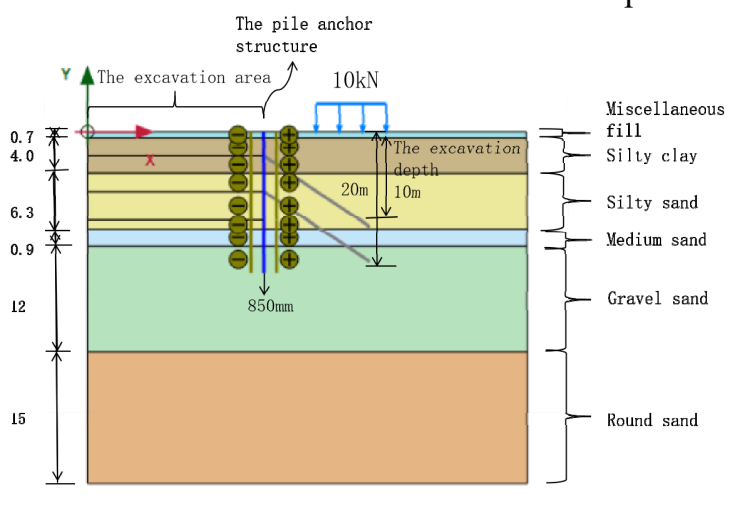

Figure. 1 Calculation model

\subsection{Calculation Steps}

In order to simulate the support section better, the simulation process and construction sequence are combined, and each excavation stage is simulated as one working condition. The concrete working conditions are as follows.

Working Condition 1: activate pile anchor and peripheral load; $3 \mathrm{~m}$;

Working Condition 2: Excavate Foundation Pit To-

Working Condition 3: Apply First Anchor Cable, prestress is $200 \mathrm{kN}$; $7 \mathrm{~m}$;

Working Condition 4: Excavate Foundation Pit To-

Working Condition 5: Construct Second Anchor Cable, prestress is $400 \mathrm{kN}$; $10 \mathrm{~m}$.

Working Condition 6: Excavate Foundation pit to-

\subsection{Analysis Of Simulation Results Of Foundation Pit}

\subsubsection{Overall deformation and stress analysis of foundation pit excavation}

As can be seen from figure 2 , the deformation of the foundation pit after excavation is mainly located at the bottom of the foundation pit, which reaches $13.47 \mathrm{~mm}$ and does not exceed the $30 \mathrm{~mm}$ warning value of the horizontal displacement of the slope top of the foundation pit in GB50497-2009, so the foundation pit is safe and reliable.

According to figure 3, we can see the obvious shear stress concentration at the bottom of the pile, the Anchorage Section of the anchor Rod and the joint of the free section. In addition, due to the gradual excavation of the foundation pit, within a certain range of the top of the slope at the edge of the foundation pit, the tensile stress concentration area will appear in the soil due to the adjustment of its own stress state, and the tensile strength is relatively low due to the properties of the soil itself, therefore, it is easy for the tensile fracture to occur and form the post-slope tension zone. With the process of stress release and adjustment, the tensile fracture will develop vertically downward, the foundation pit will appear the overall instability

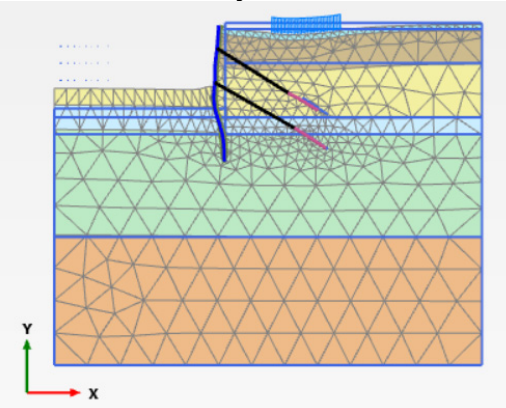

Figure. 2 Grid of foundation pit deformation

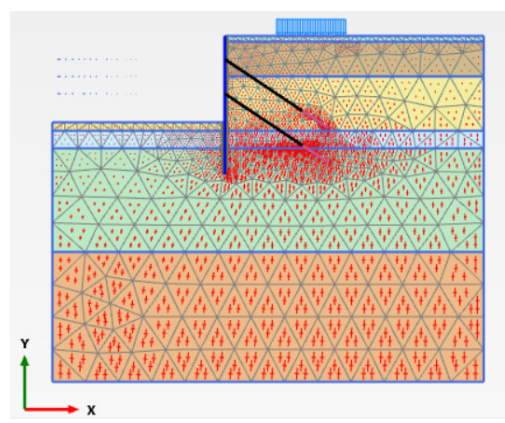

Figure. 3 stress trend of foundation pit excavation

\subsubsection{Horizontal displacement analysis of foundation pit}

1)Figure. 4 is the horizontal displacement curve of the side wall of the foundation pit. It can be seen from the graph that the displacement value changes more and more with the depth increasing, and with the depth increasing, the displacement value presents the same trend, that is, increases first and then decreases; At the position of $0-1 \mathrm{~m}$, the horizontal displacement increases quickly with the increase of the excavation depth, and the horizontal displacement of the three working conditions increases at the same rate, this is because the joint action of Anchor Cable and pile makes the displacement decrease at $1-3 \mathrm{~m}$, and then the horizontal displacement increases with the increase of excavation depth. The maximum horizontal displacement of the side wall of three excavations occurred at the positions of $1 \mathrm{~mm}, 5 \mathrm{~mm}$ and $9 \mathrm{~mm}$, and the maximum values were $1.5 \mathrm{~m}, 3.9 \mathrm{~mm}$ 
and $6.8 \mathrm{~mm}$ respectively.

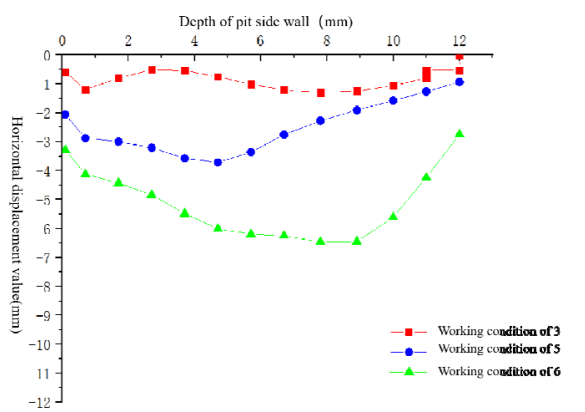

Figure.4 displacement curve of side wall of foundation pit

\subsubsection{Analysis of surface settlement outside foundation pit}

1) Figure. 5 is the surface settlement curve outside the foundation pit. It can be seen that with the increase of the excavation depth, the surface settlement curve outside the foundation pit is basically the same, first increases and then reduces to a stable value, the curve is of a spoon shape; the maximum settlement value of each excavation is about $10 \mathrm{~m}$ from the foundation pit edge, the maximum settlement value of three excavations is 4.35 $\mathrm{m}, 5.61 \mathrm{~m}, 6.8 \mathrm{~m}$ respectively, the location of the spoon handle is about $20 \mathrm{~m}$ from the foundation pit, the settlement value decreases obviously, which shows that the excavation of the foundation pit has less influence on the buildings beyond $20 \mathrm{M}$. With the increase of excavation depth, the increment of the maximum settlement is decreasing, the increment of the maximum settlement caused by the second excavation is the largest, and the third excavation is the smaller. It can also be seen from the diagram that the maximum value does not appear at the place closest to the foundation pit, this is due to the large deep deformation of the retaining structure, which makes the surface settlement at the junction between the top of the retaining wall and the surface not large. The maximum surface settlement occurs at a certain distance behind the retaining wall, forming a concave settlement pattern ${ }^{[8]}$.

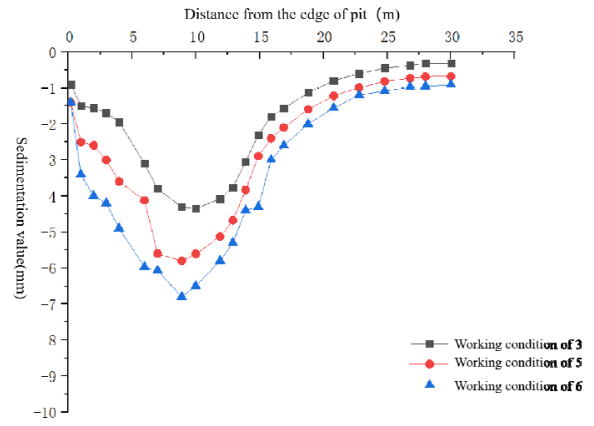

Figure. 5 surface settlement curve outside

\subsubsection{Simulation analysis of bending moment of pile body}

Figure. 6 shows the variation of pile bending moment with pile length under different excavation depth. The pile bending moment is transferred to the lower part of the pile body with the increase of the excavation depth. After the first excavation, the pile bending moment is the biggest at the pile length of $2.7 \mathrm{~m}$, and the maximum value is $52.35 \mathrm{Kn} \mathrm{m} / \mathrm{m}$ After the second excavation, the maximum bending moment is $64.75 \mathrm{Kn} \mathrm{m} / \mathrm{m}$ at the pile length of $6.7 \mathrm{~m}$ and $99.01 \mathrm{Kn} \mathrm{M} / \mathrm{m}$ at the pile length of $9.2 \mathrm{~m}$ at the bottom of the pit. The positive and negative moment increase obviously, and the maximum moment appears at the bottom of the pit, which shows that the third excavation has a great influence on the stability of the foundation pit.

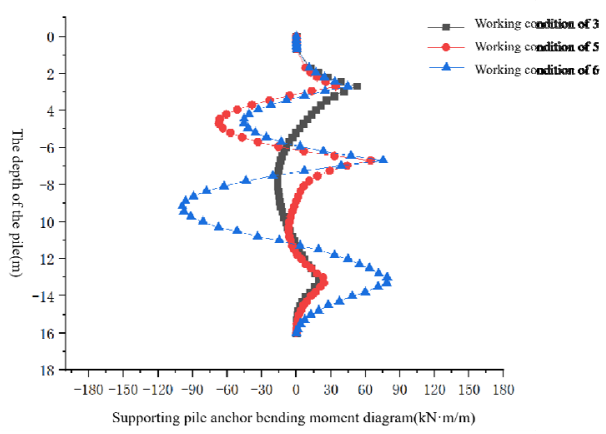

Figure. 6 Bending moment diagram of support pile anchor Foundation pit

\section{Conclusion}

1)the horizontal displacement of the side Wall of the foundation pit presents the same regularity under the different excavation depth, and the displacement changes more and more along with the excavation depth deepening, the combined action of anchor cable and pile can effectively slow down the horizontal displacement of the side wall of the foundation pit.

2)with the increase of excavation depth, the settlement value of soil outside the foundation pit also presents the same regularity, which are all spoon-shaped. The excavation of foundation pit has the biggest influence on the surface settlement around $10 \mathrm{~m}$, but has little influence on the buildings beyond $20 \mathrm{~m}$. After the excavation is completed, the value of the lateral displacement and the settlement of the soil outside the foundation pit are both smaller than the value of the code.

3 ) according to the analysis of the bending moment of pile body, the bending moment of pile body will transfer to the lower part of pile body with the increase of excavation depth, the bending moment will increase gradually, and the position of the maximum bending moment will appear in the range of $3 \mathrm{~m}$ from the pit bottom to the pit bottom. The third excavation has a great influence on the stability of the foundation pit, and the force on the lower part of the pile is obvious with the deepening of the excavation.

\section{Acknowledgements:}

Support was provided by the College of Civil 
Engineering and Architecture, Hebei University, Baoding, Hebei 071002, China (826007557@qq.com). Funding was provided by Study on damage mechanism and evolution rule of granite under hydrothermal coupling cycling (HBU2021ss029) and Post doctoral program of human resources and social security department (B2020003028).

\section{References:}

1. Wang Song, Xie Xicheng, Zhou Siguang, et al. Simulation Analysis of Supporting structure of Deep Foundation Pit based on FLAC [J]. Reconnaissance Science and Technology, 2017(3): 6-10, 26.

2. Liu Jie, YAO Hailin, Ren Jianxi. Deformation Monitoring and Numerical Simulation ofsubway Station Foundation Pit Enclosure [J].Rock and Soil Mechanics, 2010, 31(+2): 456-461.

3. Xia Jinhua, YUE Pengwei. Numerical Analysis of displacement of Pile-anchor Supporting System for Deep Foundation Pit [J]. Journal of Underground Space and Engineering, 2014, 10(4): 848-853.

4. Liu Jie, YAO Hailin, Ren Jianxi. Subway station foundation pit retaining structure deformation monitoring and numerical simulation $[\mathrm{J}]$. Rock and soil mechanics, 2010, 31 (S2): 456-461. The DOI: 10.16285 / sm j.r. 2010. S2.008.

5. Fang Shi Jun, Fu Jian Jun, Yao Aijun. Journal of geotechnical engineering,2011,33(S1):223-226. (in Chinese).

6. Lu Hui. Numerical Simulation of pile-anchor Support for deep foundation Pits [J]. Anhui Architecture, 2018, 24(3): 236-238.

7. Zheng Xiaoyan, XIA Jian, Chen Chunshu. Numerical Simulation analysis of Pile anchor Support Parameter Optimization for Foundation Pit [J]. Railway Construction Technology, 2016(10): 74-78.

8. Wang Weidong, $\mathrm{Xu}$ Zhonghua. Journal of geotechnical engineering,2010,32(S1):32-38. (in Chinese). 